\title{
Profile of the companies participating in the Mexican national exports award
}

\author{
Orduño-Soto, Carmen L. ${ }^{1}$; Leos-Rodríguez, Juan A. ${ }^{1}$; Martínez-González, Enrique G. ${ }^{1}$; \\ Aguilar-Ávila, Jorge ${ }^{1}$ \\ 1 Universidad Autónoma Chapingo, Km. 38.5 Carretera México-Texcoco, C.P. 56230. \\ * Correspondence: jleos45@gmail.com
}

Citation: Orduño-Soto, C. L., LeosRodríguez, J. A., Martínez-González, E. G. \& Aguilar-Ávila, J. (2021). Profile of the companies participating in the Mexican national exports award. Agro Productividad. https://doi.org/ 10.32854/ agrop.v14i10.1919

Editor in Chief: Dr. Jorge Cadena Iñiguez

Received: February 2, 2021

Accepted: August 14, 2021.

Published on-line: November 8, 2021

This work is licensed under a

Creative Commons Attribution-Non-

Commercial 4.0 International license.

\begin{abstract}
Objective: To identify the profile of the companies participating in the Mexican National Exportation Award (NEA) in the Large Agricultural Exporting Companies category (LAEC), by an information-gathering tool to determine the commercial lines of those businesses, their state of origin, and the exports destination.

Methodology: A total of 17 questionnaires $(n=17)$, applied by the NEA to the LAEC category participants during the 2010-2018 period, were analyzed to determine the commercial business lines, their state of origin, and the destination of the exports. A problem tree was created to find opportunity areas to design solution proposals. The collected information was processed in the NetDraw 2.097 software to show the networks, their dominant actors (countries to which they export), and the products that the companies exported the most.

Results: pork and vegetables business lines were identified. The latter revealed a sub-network of tomatoes and strawberries. A network was generated with an open structure comprising 17 nodes and 46 links where three export destination countries stood out: the USA with 15 links, Canada with six, and Japan with five. The highest exported product was the tomato in its different varieties, mainly to the U.S. and Canada.

Limitations: Scarce information about the award on the internet. Access restrictions. Most of the exporting companies did not respond to the survey.

Conclusions: The perishability of exported products determines the number of destination countries. The precariousness of Mexican agricultural exports was identified because companies trade only one product or a reduced number of them to only one country.
\end{abstract}

Keywords: Precariousness, Innovation, Networks.

\section{INTRODUGTION}

International trade consists of the analysis of the different aspects related to the exchange of goods and services between people residing in different countries. That is, which goods a country exchanges in the international markets, with which countries, and in which quantities (Bajo, 1991). International trade in Mexico plays an important role in its 
economy, since it is a driving force for economic development; however, to ease this activity, it is necessary to create treaties that allow commercial exchange between Mexico and other countries. Free trade agreements usually incorporate rules on goods trade, services, investment, intellectual property, trade defense mechanisms, and most importantly, dispute settlement. Some recent ones include labor and environmental dispositions (COMEX, 2004). Michael Porter (2007), through his competitiveness diamond model, states that a country's competitive advantage is “...its ability to encourage local and foreign companies to use such a country as a platform for carrying out their activities". Amit and Zott (2001) state that competitiveness is the ability of a company to position and maintain itself in the market in the long term. Therefore, competitive advantages are created by improving efficiency and creating more valuable products. Exports have a certain improvement level, supporting those companies still developing in this area to increase their exporting capacity is important. Park and Urmeneta (2019) point out that a potential cause of export instability is that companies sell only one product to only one destination; both of which are precariousness indicators.

The Social Network Analysis (SNA) attempts to analyze how individuals or companies are connected, to determine the network's general structure, the network's group, and the individuals' position or the company to delve into the social structure that underlies the information flow, interchanges, or power (Menéndez, 2003).

The NEA was created to annually award the effort, tenacity, creativity, and innovation of the companies and educational institutions that participate in exporting. It began with eight categories, but over the years new ones were added and some were eliminated. Currently, 12 categories are available to participate. To give this important recognition to companies, institutions, and leading organizations in foreign trade a new direction and a new impulse, in 2009, Secretaría de Economía (Ministry of Economy), through the Subsecretaría para la Pequeña y Mediana Empresa (Undersecretariat for Small and Medium Enterprises), granted the responsibility for the organization, promotion, and dissemination of the award to the Fundación Premio Nacional de Exportación A.C. (National Export Award Foundation A.C., FPNE, 2009). The FPNE's founding organizations are five of the country's most important and linked to exporting companies: The Consejo Empresarial Mexicano de Comercio Exterior, Inversión y Tecnología (Mexican Business Council for Foreign Trade, Investment and Technology, COMCE), the Confederación de Cámaras Industriales de los Estados Unidos Mexicanos (Confederation of Industrial Chambers of the United States of Mexican, CONCAMIN), the National Agricultural Council (National Agricultural Council, GNA), the Consejo Coordinador Empresarial (Business Coordinating Council, CCE) and the Confederación de Cámaras Nacionales de Comercio y Turismo (Confederation of National Chambers of Commerce and Tourism, CONGANACO SEYTUR) (PNE, 2009). The objective of this research was to analyze the profile of the companies participating in the NEA under category $\mathrm{V}$, through an information collection tool to identify business lines, states of origin, and export destination countries, to develop an improvement strategy that will enable the NEA to achieve better results. 


\section{MATERIALS AND METHODS}

The data collection was conducted by extracting information from 17 questionnaires applied to the companies participating in category V (Large Agricultural Exporting Companies) from 2010 to 2018 in the NEA. The questionnaire consisted of 10 openended questions. A spreadsheet was created to systematize the information about products, amounts, and percentages they represent in the export of the companies, identify the countries where they export to, their logistics, innovations made (on their processes, product or service), among other aspects.

For the data analysis, descriptive statistics were used, and graphics were developed. Using the generated spreadsheet database, the information was also organized to construct an export network through the network generator question: "principal destination countries for exports" and through the export network, sub-networks were created to illustrate the export destinations of each line of business. The networks were generated through the NetDraw 2.097 software. The calculation of ARS indicators like network size and the number of links was performed by the UCINET 6 for Windows ${ }^{\circledR}$ version 6.288 software.

Likewise, word clouds were created using the data collection tool, to show the most frequently mentioned words by the participating companies under the $\mathrm{V}$ category of the NEA. As the questionnaire applied by the award contained open-ended questions, processing them became difficult; therefore, the word clouds were created using the "Wordle" software. The answers given by the participating companies in the category V of the NEA were selected (question by question), then these answers were uploaded into the Wordle software to generate word clouds. A folio was assigned for each company to avoid mentioning names and protect the privacy of the obtained information, as well as the type of exported product (horticultural and animal husbandry).

\section{RESULTS AND DISCUSSION}

\section{Attributes of companies participating in the NEA}

As for the participation by business line among the companies under the LAEC category, vegetables are in first place with 12 companies, or $70.6 \%$ from the total number of participants (17), followed by the swine husbandry sector with three companies, representing $17.6 \%$, and last, the fruits sector with two-company participation, 11.8\%. Considering the year of participation within the 2010-2018 interval, the years 2012, 2013 and 2017 stand out with the participation of three agribusinesses for each year, representing $52.9 \%$ of the total, followed by 2011 and 2015 with a participation of two agribusinesses each year, i.e. 23.5\% of the total. Finally, 2010, 2014, 2016, and 2018 with the participation of one agribusiness for each year, representing $23.5 \%$ of the total.

As for participation by state, Sinaloa stands out with 35.3\%, followed by Mexico City with $17.6 \%$ and Baja California with 11.8\% (Figure 1).

\section{Activity dynamics}

The most exported product by the NEA participating companies in the $\mathrm{V}$ category during the 2010-2018 period was tomato, in its different varieties (saladette, ball, cherry, among others), in second place beef, and bell peppers in third place. 


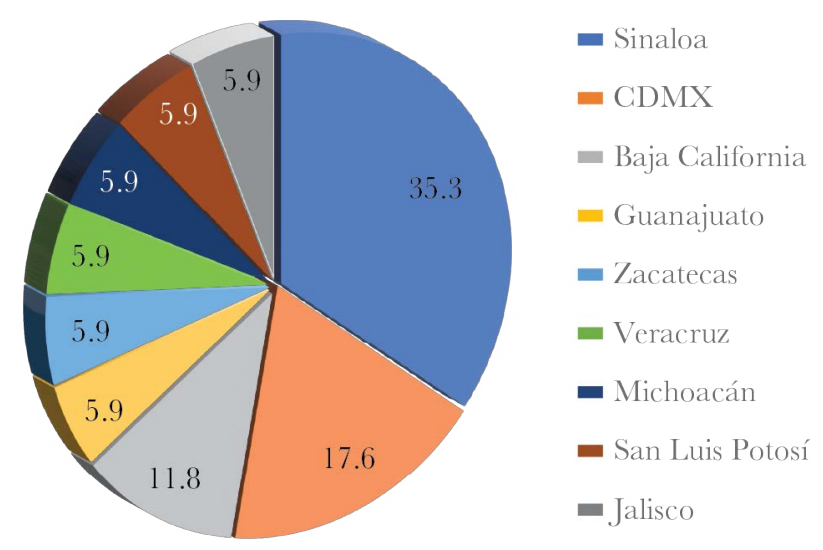

Figure 1. Participation by state in the NEA, category V, 2010-2018.

Regard the exports destination, during the year each company's participated in the NEA, the results showed that $82.4 \%$ of vegetables and fruits were exported to the U.S., pointing out some companies' precariousness. Park and Urmeneta (2019) indicate that a cause of export instability is the fact that companies sell a single product to a single destination, both of which are indicators of precariousness.

Forty-seven percent of the companies participating in the NEA mentioned having certification in Good Agricultural Practices (GAP), Good Manufacturing Practices (GMP), and Hazard Analysis and Critical Control Point System (HACCP).

As for the quality control processes of each company, a word cloud was generated, emphasizing answers such as good practices, safety, product, quality.

About the strategy to access new markets, the answers that stood out among the NEA participating companies were: comparison, needs, customers, price, among others.

\section{Innovation dynamics}

According to the Oslo manual (2008), a technological innovation comprises new products (goods and services), processes, and significant technological changes to those products and processes. Innovation has been implemented if it has been introduced into the market (product innovation) or used within the production process (process innovation). Therefore, innovations involve a series of scientific, technological, organizational, financial, and commercial activities.

The responses to find out what were the different kinds of innovations implemented by the companies participating in the NEA emphasized the following: production, processes, products, and selection (Figure 2).

The word clouds were helpful because the questionnaires applied by the NEA contain open-ended questions, making it difficult to process them. The word clouds were used to visualize the most frequently mentioned by the companies that participated in the NEA.

\section{Commercial Network Analysis using ARS}

A total of 17 horticultural and swine husbandry companies were surveyed. They were asked to enlist the countries to which they export their products, giving a total of 18 . 


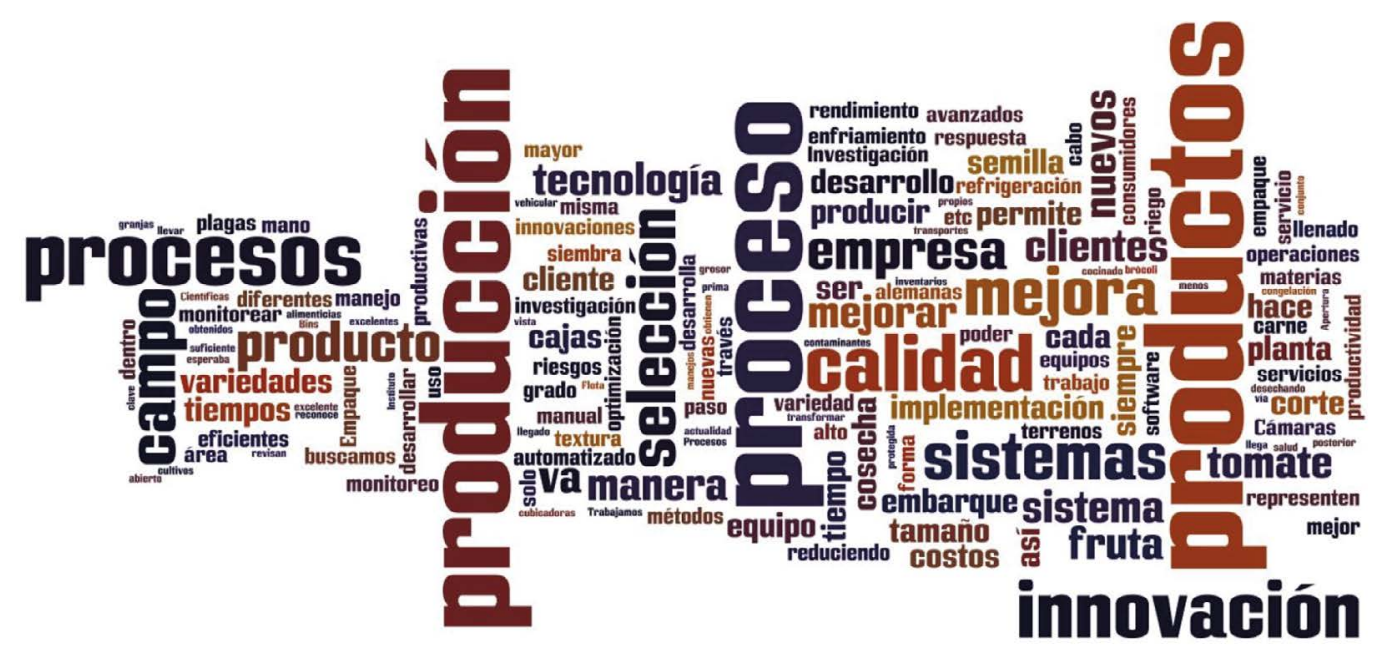

Figure 2. Principal innovations implemented by NEA participating companies in the V category, 2010-2018.

\section{Export network}

An open structure network was generated, composed of 17 nodes and 46 edges. Four actors stand out in the network: AI03-16, AI06-18, AI07-17 and AI02-15, which export to the largest number of countries (Figure 3). The companies are shown in red, the countries in blue and the actors that stand out in the network in lime-green.

The network was subdivided into three sub-networks (tomato network, fruits network, and beef network) to show that the perishability grade largely determines the number of destination countries and their proximity. For example, the tomato export destination is only the USA, while fruits, including blueberries which have a lower degree of perishability, allow a wide range of destinations and distances; finally, meat,

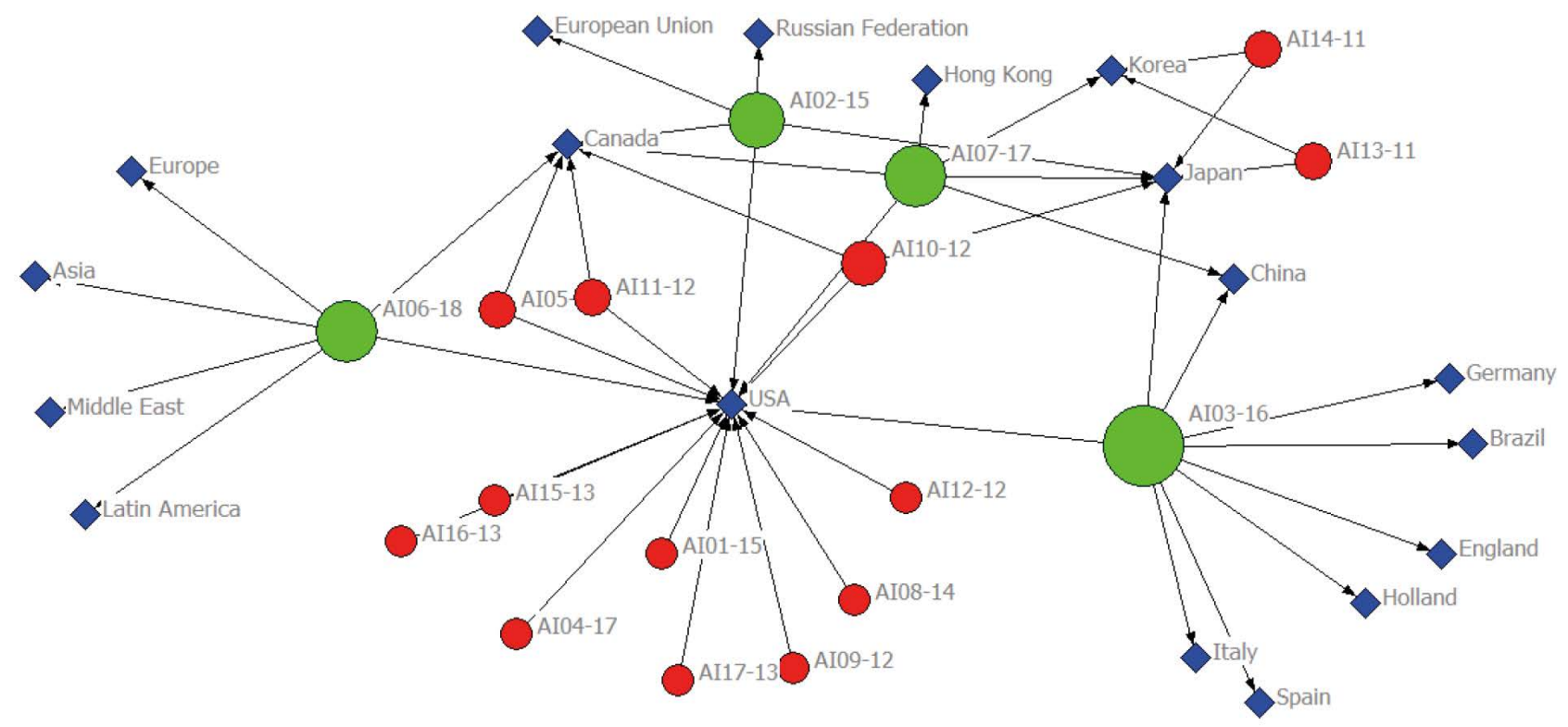

Figure 3. Export network of companies participating in the NEA, category V, 2010-2018. 
including frozen products, makes it a non-perishable product compared to tomatoes and some fruits or berries, and therefore its network represents a diversity of export destination countries, attenuating the precariousness index that Mexican exports, especially agricultural exports, shown in overall. In the Ahern virtual symposium, Engineer Alfredo Diaz mentioned that "...Mexico needs to be less vulnerable because it depends on a single market, which is the U.S. Of the $80 \%$ of agricultural production, 96\% is exported to the U.S. and 4\% to Canada". Demonstrating that agricultural exports have only one market, "the American market" (Seeds, 2020).

Figures 4, 5, and 6 show the network divisions that were made. The companies are shown in red and the countries in blue.

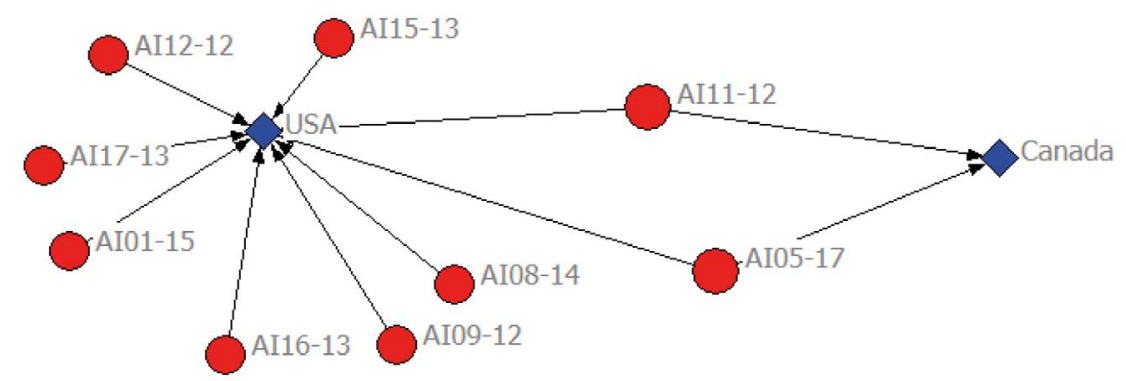

Figure 4. Tomato export network of the NEA participating companies, category V, 2010-2018.

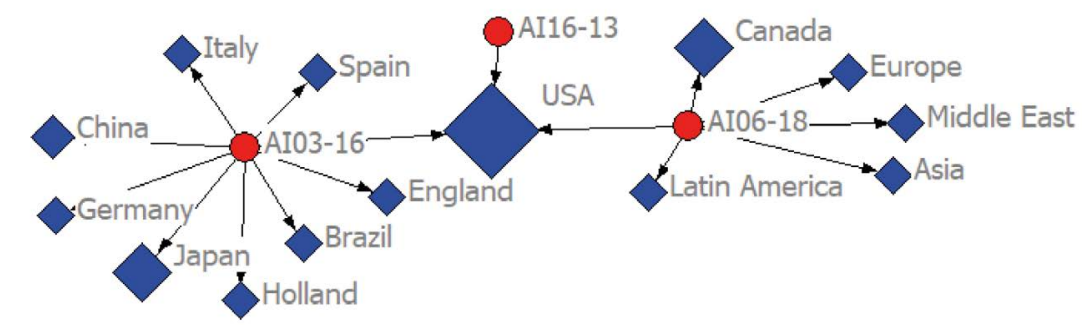

Figure 5. Fruits export network of the NEA participating companies, category V, 2010-2018.

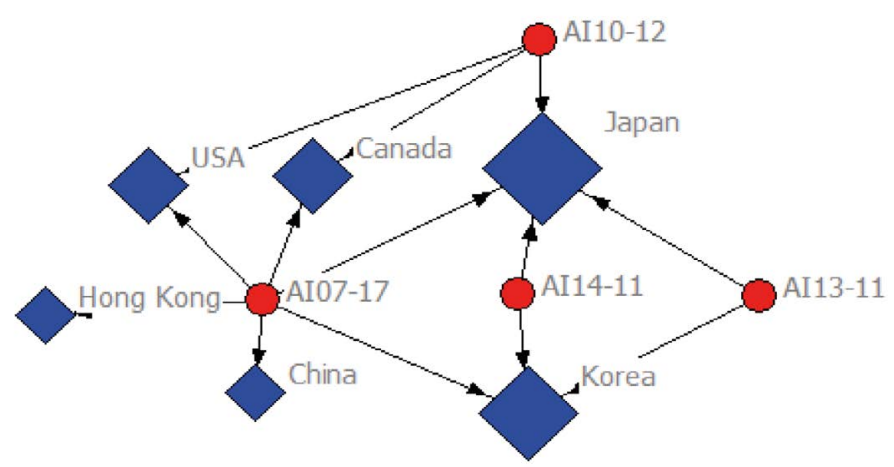

Figure 6. Meat export network of the NEA participating companies, category V, 2010-2018. 


\section{CONGLUSIONS}

The analysis of the NEA participating companies indicated the precariousness of the agricultural sector as it exports only one product or a reduced number of them to a single country, due to the perishability of most of the products and the geographical proximity to the world's largest market. This one-way flow of Mexican agricultural exports will probably continue or increase due to the pandemic. The same could happen for the rest of them and even for imports. Low participation by States and by business lines was also observed. In the nine assessed years, only nine States and two lines of business participated. The possible reason for this could be the lack of promotion of the NEA.

This study had some limitations, such as the scarce information on the award, which would serve for future research; some companies that won the NEA in the LAEC category did not want to answer the requested survey, this would have been of great help for better understanding the NEA process, and most importantly, the opinion that these companies have about the award. Interviews with other similar awards were also missing to evaluate them and understand what their business model is like and observe opportunity areas for the NEA. These aspects limited the realization and scope of the present research. From the obtained results, it is proposed that the dissemination by social networks be increased, as well as the participation in fairs, forums, expositions, and state awards. This is expected to increase the participation of companies from different sectors and different regions of the country.

\section{ACKNOWLEDGEMENTS}

To the Universidad Autónoma Chapingo and the Centro de Investigaciones Económicas, Sociales y Tecnológicas de la Agroindustria y la Agricultura Mundial (CIESTAAM) for providing the author the opportunity to participate in the Master's Program for Agribusiness Strategy.

\section{REFERENCES}

Amit, Raphael, and Christoph Zott. 2001. "Value Creation in E-Business." Strategic Management Journal. Bajo, O. 1991. "Teorías Del Comercio Internacional - Oscar Bajo - Google Libros.” Retrieved October 27, 2020 (https://books.google.com.mx/books?hl=es\&lr=\&id=99HyPYGM5EUC\&oi=fnd\&pg=PA $9 \& \mathrm{dq}=$ comercio + internacional\&ots $=$ cv0yvbvBlI\&sig=y0MsusG2cdJnfTgiVsI9v9D2Xvo\&redir $\mathrm{esc}=\mathrm{y} \# \mathrm{v}=$ onepage $\& \mathrm{q}=$ comercio internacional\& $\mathrm{f}=$ false).

COMEX. 2004. "Tratado de Libre Comercio Entre Los Estados Unidos y Chile." 1-24.

FPNE. 2009. "Modelo Del Premio Nacional de Exportación 1.” 1-51.

Menéndez, Luis Sanz. 2003. "Análisis de Redes Sociales : O Cómo Representar Las Estructuras Sociales Subyacentes." Networks.

OCDE. 2008. "El Manual de Oslo y La Innovación Social.” Arbor (732):609-18.

Park, Hyunju, and Roberto Urmeneta. 2019. "El Desempeño de Empresas Exportadoras Según Su Tamaño: Una Guía de Indicadores y Resultados." Documentos de Proyectos.

Porter, Michael. 2007. "Ventaja Competitiva." Competitive Strategy.

Seeds, Ahern. 2020. "Simposio Virtual Ahern, Conectándote En Ambos Lados de La Frontera." Retrieved (https://www.youtube.com/watch?reload=9\&v=iwjcx5DUodY\&feature=youtu.be\&t=729\&utm _ source=YouTube\&utm_medium=Agtech\&utm_campaign=sasq2020Alfredo). 